
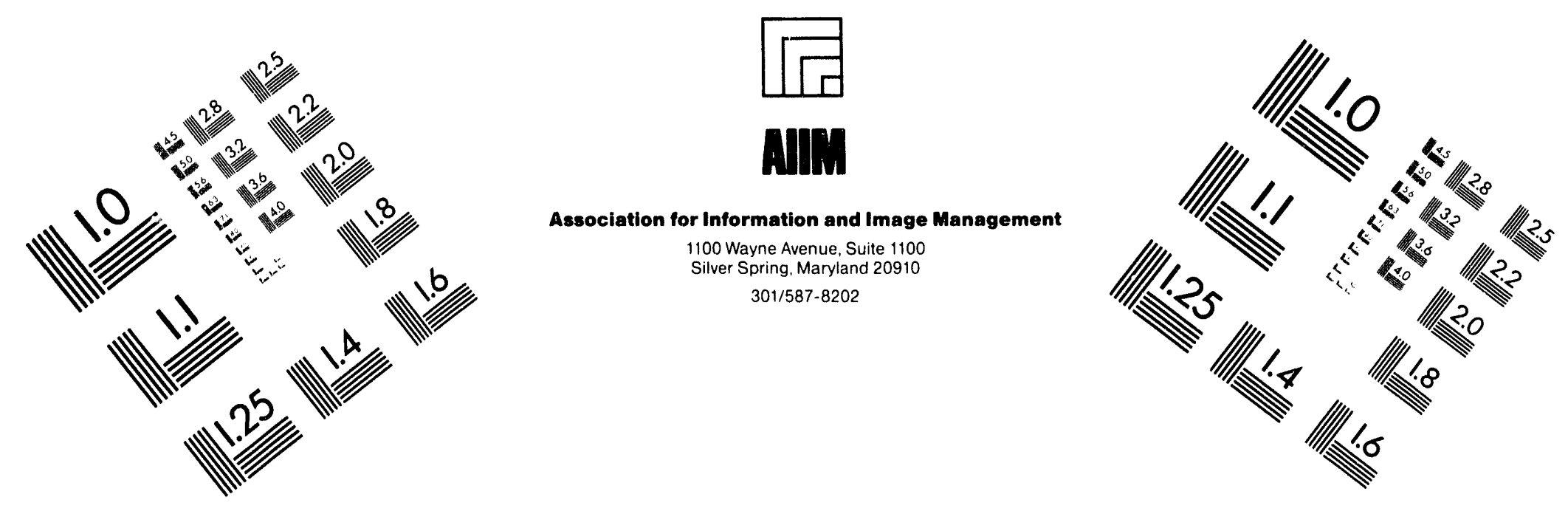

\title{
Centimeter
}

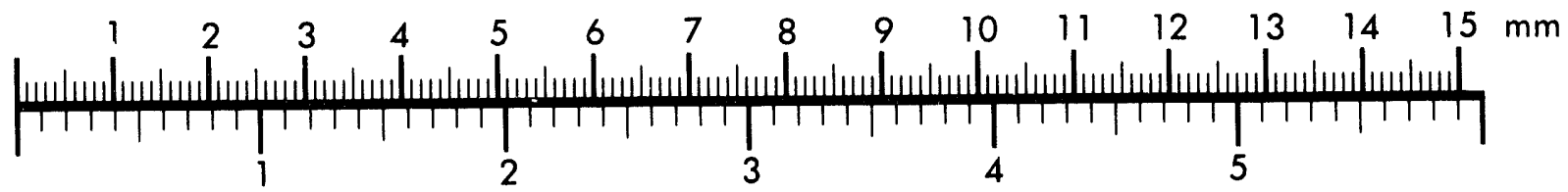
Inches
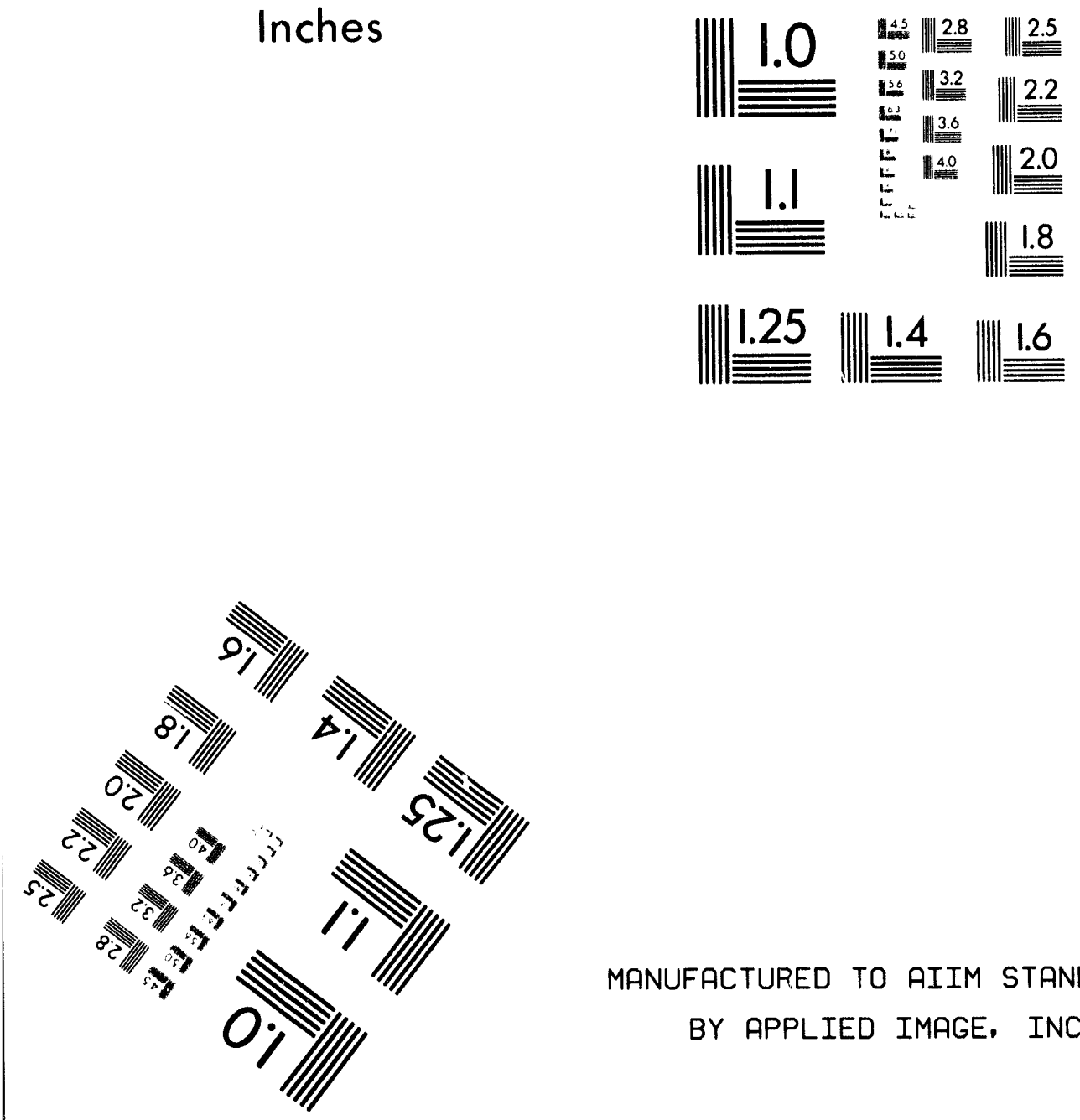

MANUFACTURED TO AIIM STANDARDS

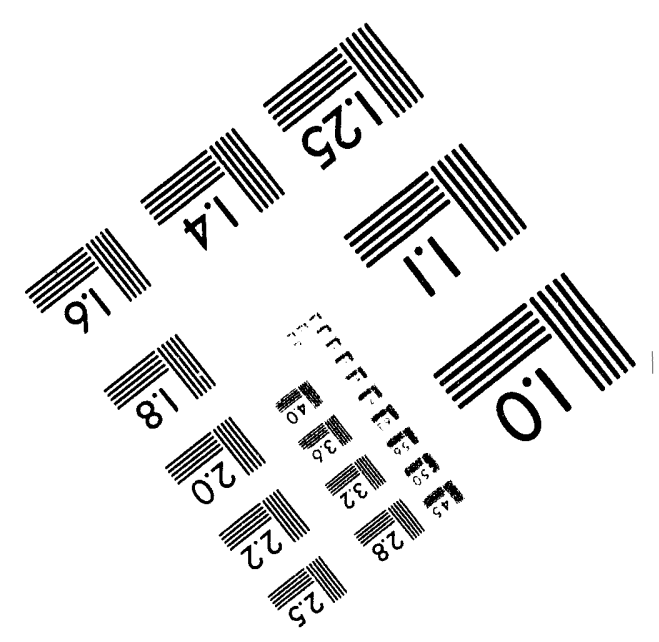



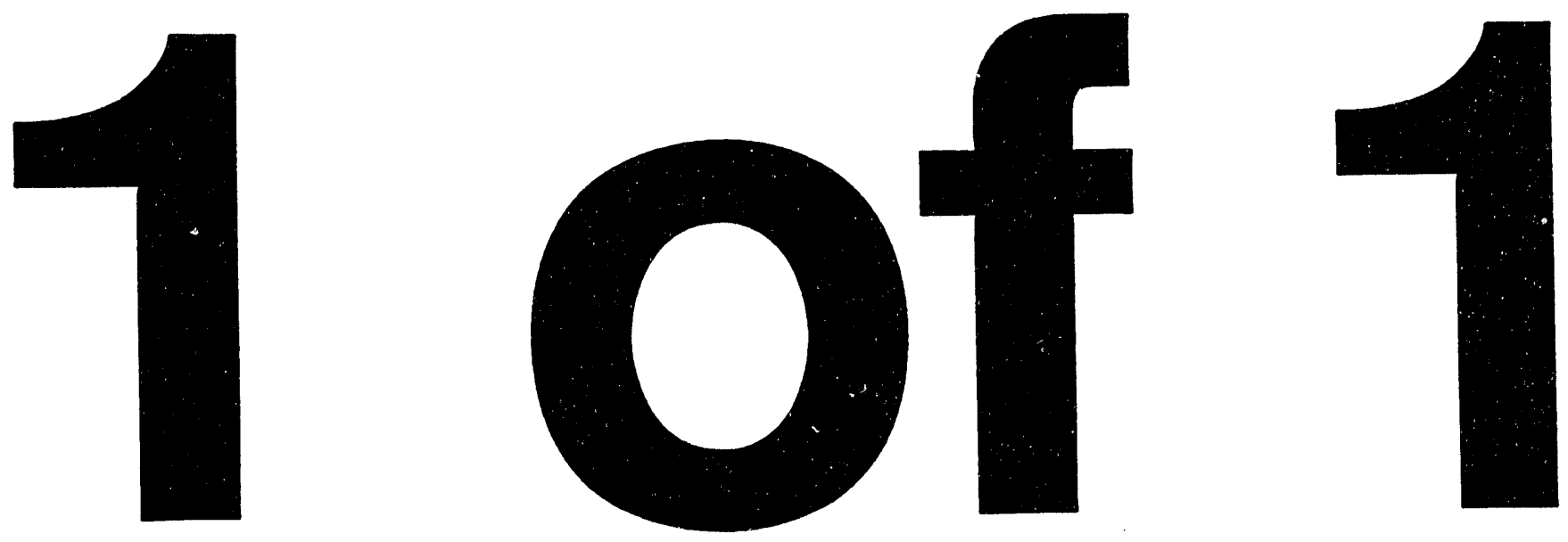


\title{
Corf $-9407103-28$
}

\section{MOLTEN FLUORIDE FUEL SALT CHEMISTRY}

\author{
L. M. Toth, G. D. Del Cul, S. Dai, and D. H. Metcalf \\ Chemical Technology Division \\ Oak Ridge National Laboratory \\ Oak Ridge, Tennessee 37831-6181
}

\begin{abstract}
The chemistry of molten fluorides is traced from their develonment as fuels in the Molten Salt Reactor Experiment with important factors in their selection being discussed. Key chemical characteristics such as solubility, redox behavior, and chemical activity are explained as they relate to the behavior of molten fluoride fuel systems. Fission product behavior is described along with processing experience. Development requirements for fitting the current state of the chemistry to modern nuclear fuel system are described. It is concluded that while much is known about molten fluoride behavior, processing and recycle of the fuel coinponents is a necessary factor if future systems are to be established.
\end{abstract}

\section{Introduction}

Molten fluoride fuel salts were developed and utilized more than twenty five years ago originally for use in the Aircraft Nuclear Project and finally, in the Molten Salt Beactor Experiment, MSRE. A considerable R\&D effort was devoted to these systems during the 1950's and 1960's which culminated in the construction and operation of the MSRE during the late 1960 's. After shutdown of the MSRE in late 1969, research on fluoride systems was drastically curtailed, even in fundamental studies. However, after a 25 year hiatus, there has been renewed interest in utilizing molten fluoride solutions in nuclear applications because of the same unique advantages that were recognized decades ago.

This paper will summarize the key features in molten fluoride chemistry that makes it desirable for application to such nuclear systems. The significant chemical characteristics of molten salts will be described along with their impact on the design of a molten salt reactor system. The presentation of these characteristics will be integrated with fundamental chemical principles which help to determine them and the necessary measurements will be listed. In addition, the final post-mortem experience will be discussed in view of the fundamental inorganic chemistry which has evolved since 1970 . Finally, the current needs in further molten fluoride R\&D will be addressed in order to fulfill the goals in utilizing molten fluorides for ADTT requirements.

Much of the development of MSRE molten fluoride chemistry was under the leadership of the late, Warren E. Grimes. This presentation follows much of the plan he had initially outlined and many of the results which were obtained by him; and, therefore, it is fitting that this be dedicated to his memory.

Molten Salt Reactor Experiment

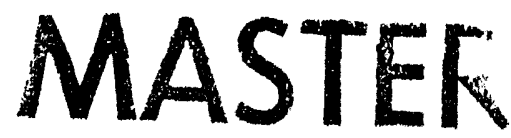

Figure 1 shows a cutaway of the MSRE which consists of a primary loop containing approximately 4 tons $\left(4650 \mathrm{Kg}\right.$ or approximately $\left.2 \mathrm{~m}^{3}\right)$ of molten salt, $\mathrm{LiF}-\mathrm{BeF}_{2}-\mathrm{ZrF}_{4}-\mathrm{UF}_{4}(64.5$ - 


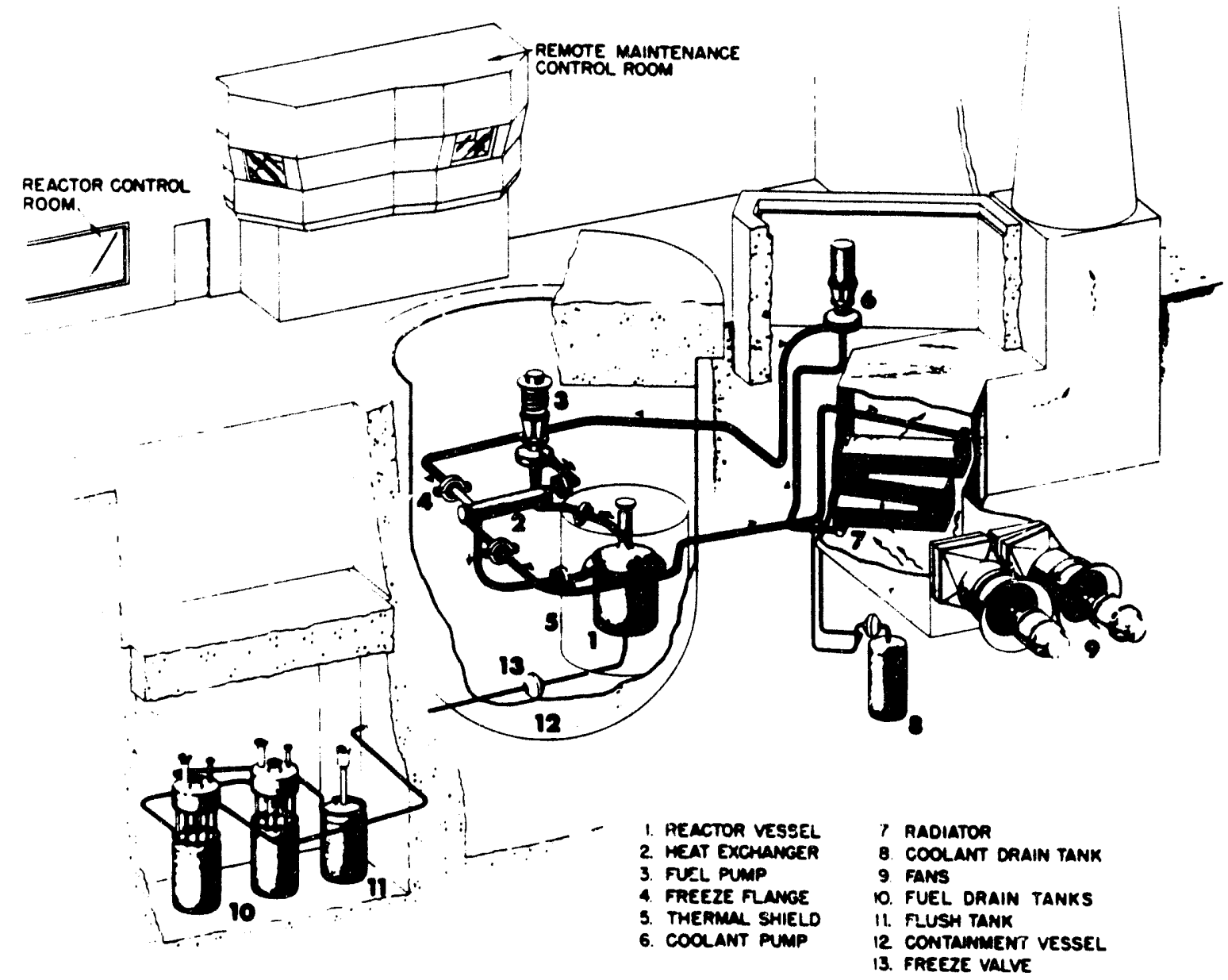

Fig. 1. Cutaway view of the Molten Salt Reactor Experiment circuitry.

\section{DISCLAIMER}

This report was prepared as an account of work sponsored by an agency of the United States Government. Neither the United States Government nor any agency thereof, nor any of their employees, makes any warranty, express or implied, or assumes any legal liability or responsibility for the accuracy, completeness, or usefulness of any information, apparatus, product, or process disclosed, or represents that its use would not infringe privately owned rights. Reference herein to any specific commercial product, process, or service by trade name, trademark, manufacturer, or otherwise does not necessarily constitute or imply its endorsement, recommendation, or favoring by the United States Government or any agency thereof. The views and opinions of authors expressed herein do not necessarily state or reflect those of the United States Government or any agency thereof. 
30.3-5.0-0.13 mole\%) which was pumped through the core by the fuel pump and on to the heat exchanger. The $2610 \mathrm{Kg}$ of corlant salt was pumped by the coolant pump from the heat exchanger to the radiator where fans blew the $7.5 \mathrm{MWt}$ power generated up the stack. The molten fuel mixture varied from $550-650^{\circ} \mathrm{C}$ in the circuit. Two significant features of this system should be noted: First, the fuel pump not only provided the circulation of the fuel but also provided ready access to salt sampling and addition through the pump bowl cavity. (See Fig. 2 discussion in the following paragraph.) Second, at termination of the MSRE experiment in 1969 the fuel salt was split by draining into the two fuel drain tanks and allowed to solidify. It has remained there for the past 25 years.

A cutaway drawing of the pump bowl is shown in Fig. 2. It provided easy access for routine sampling, fuel additions and inert gas sparging. The first two operations were achieved by lowering a sample capsule attached to a wire cable down an access pipe and into the sample capsule cage. There the sample capsule would flood with salt (for sampling) or release its contents by melting (for additions). The access point was farthest from the high radiation levels in the reactor vessel and, thus, could be routinely used on a weekly/monthly basis. Finally, inert gas sparging of the pump bowl contents through the bubbler enabled the removal of the noble gases, $\mathrm{Kr}$ and $\mathrm{Xe}$ into the offgas line.

\section{General Requirements for the Molten Salts}

A molten salt reactor makes the following stringent minimum demands upon its fluid fuel. The fuel must consist of elements of low (and preferably very low) capture cross section for neutrons typical of the energy spectrum of the chosen design. The fuel must dissolve more than the critical concentration of fissionable material at temperatures safely below the temperature at which the fuel leaves the heat exchanger. The mixture must be thermally stable and its vapor pressure must be low over the operating temperature range. The fuel mixture must possess heat transfer and hydrodynamic properties adequate for its service as a heat-exchange fluid. It must be relatively non-aggressive toward some otherwise suitable material --- presumably a metal --of construction and toward some suitable moderator material. The fuel must be stable toward reactor radiation, must be able to survive fission of the uranium --- or other fissionable materials --- and must tolerate fission product accumulation without serious deterioration of its useful properties. In order to be economical, there must be a low fuel cycle cost which presupposes a cheap fuel and an effective turn-around of the unburned fissionable material or (more reasonably) an effective and economical decontamination and reprocessing scheme for the fuel.

\section{Choice of the Fuel Composition}

Of all the compounds that could be used as high temperature fluids in reactor systems, fluorides best emcompass the properties of stability, low vapor pressure, reasonable melting points, and low neutron cross section. These characteristics are summarized in Table 1 for severa: candidate fluorides from which the $\mathrm{LiF}, \mathrm{BeF}_{2}$, and $\mathrm{ZrF}_{4}$ components were optimal. (The inclusion of $\mathrm{ZrF}_{4}$ will be discussed later in more detail.) Chlorides could offer another possible route to molten salt systems but when (1) usefulness of the element, $\mathrm{Cl}$, without isotope seperation, (2) better neutron economy, (3) higher chemical stability, (4) lower vapor pressure, 

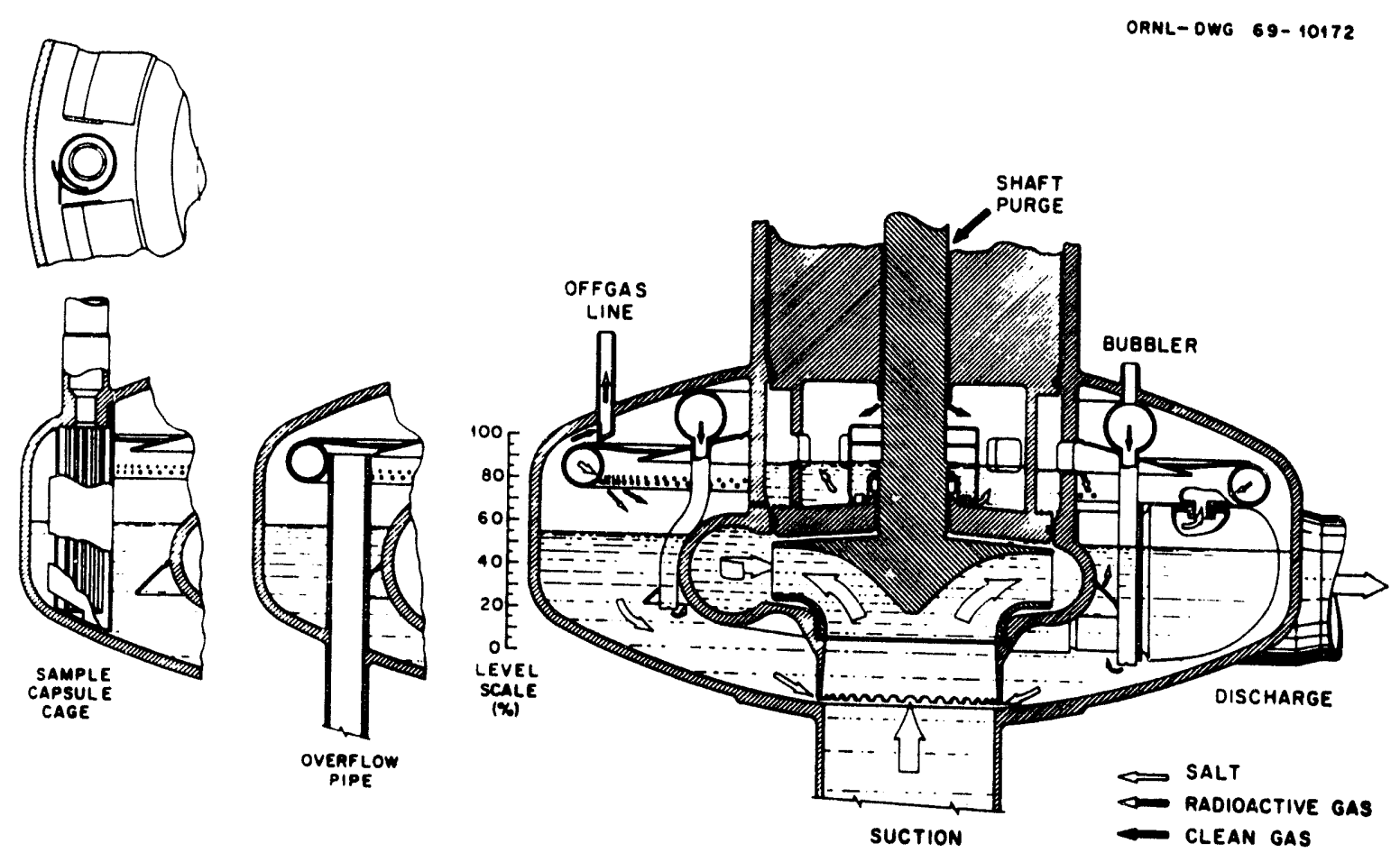

Fig. 2. Cutaway view of the Molten Salt Reactor Experiment fuel pump bowl. 
Table 1. Relevant Properties of Fluorides in the Selection for use in High Temperature Reactors

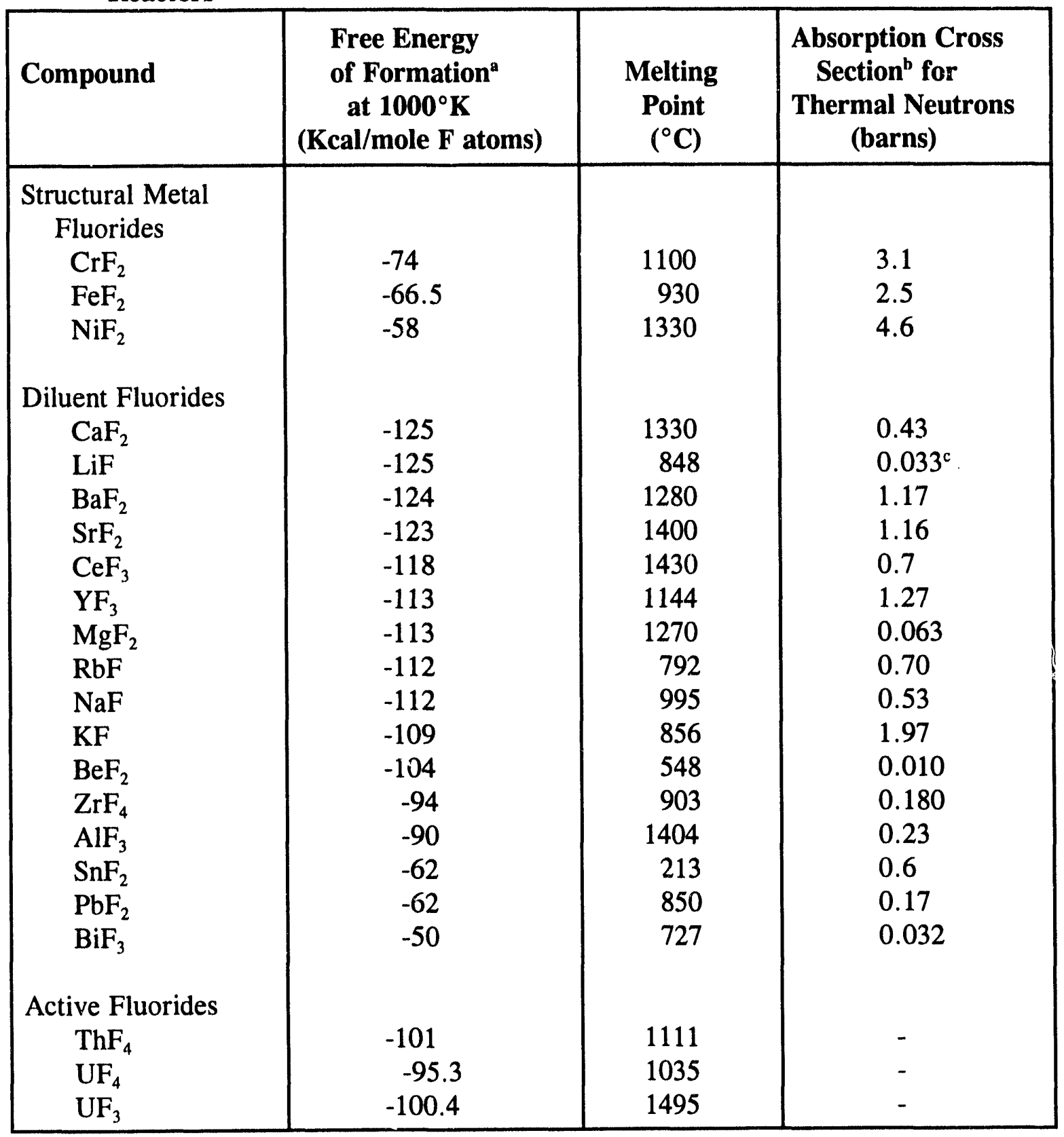

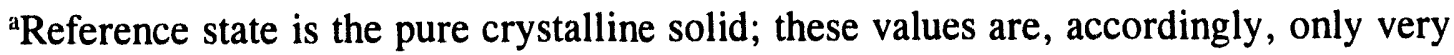
approximately those foi solutions in molten mixtures.

${ }^{\mathrm{b}} \mathrm{Of}$ Metallic ion.

${ }^{\mathrm{c}}$ Cross section for ${ }^{7} \mathrm{Li}$.

and (5) higher heat capacity per unit weight or volume are considered, fluorides have an obvious advantage. 


\section{Chemical Considerations}

Three important chemical cuncepts play a major role in controlling the behavior of the MSRE fuel. These are solubility, redox chemistry, and chemical activity.

Solubility. Solubility takes on a broad meaning in molten salt considerations since the major concern is to keep the components, especially the fuel entity, in a homogeneous molten solution during reactor operation. For pure, unreacting salts solubility is determined by the melting point of the mixture and consequently, the determination of such melting point as a function of salt composition played a dominant role in the early R\&D stages of reactor design. The phase diagram of the two major MSRE solvent components is shown in Figure 3.

As seen by the composition vs. temperature relationships a lower melting solution can be obtained with mixtures of the salts as opposed to the pure components. Furthermore, the composition dependence of insolubility is better understood by examining the figure where it is seen that for compositions such as $\mathrm{LiF}-\mathrm{BeF}_{2}(80-20$ mole \%) pure $\mathrm{LiF}$ would be the insoluble component (or "primary phase") if the melt fell below $710^{\circ} \mathrm{C}$. On the other hand, at the $60-40$ mole \% composition, $\mathrm{Li}_{2} \mathrm{BeF}_{4}$ would be the insoluble phase if the temperature fell below $440^{\circ} \mathrm{C}$. For criticality control and safety, it is highly desirable that the primary phase (the first solid phase that precipitates out on cooling) not contain the fuel component. While this was achieved with the MSRE for the $\mathrm{UF}_{4}$ component, it is less certain for $\mathrm{PuF}_{3}$ fuels which have apparent solubilities of approximately 1 mole \% in most molten fluoride solvents at typical operating temperatures.

From melting point (or solubility) considerations alone the $\mathrm{LiF}_{-} \mathrm{BeF}_{2}(48-52$ mole \%) eutectic composition would be most desirable with its $360^{\circ} \mathrm{C}$ melting point. However, for this particular system the melt viscosity becomes progressively higher due to the formation of a $-\mathrm{BeF}_{4}$ - network in the fluoride-deficient environment where fluoride atoms are shared between adjacent $\mathrm{Be}$ atoms while satisfying the necessary four coordination requirement of $\mathrm{Be}$. (See the discussion on chemical activity.) Therefore the $2: 1$ ratio of $\mathrm{LiF}: \mathrm{BeF}_{2}$ composition offers the best compromise between acceptable melting point and viscosity. (At this composition, there is ample fluoride to satisfy the four coordinate requirement for $\mathrm{Be}$, ie. $\mathrm{BeF}_{4}{ }^{2-}$ without sharing $\mathrm{F}^{-}$.

In addition, chemical reaction of the fluoride with impurities (eg., moisture) or system components (eg., graphite) can form metal oxides or carbides which have a much higher melting points and therefore appear as insoluble components at operating temperatures. Reactions of the fuel component with water vapor:

$$
2 \mathrm{H}_{2} \mathrm{O}_{(\mathrm{g})}+\mathrm{UF}_{4} \rightleftarrows \mathrm{UO}_{2}+4 \mathrm{HF}_{(\mathrm{g})}
$$

are of particular concern because they result in the formation of the insoluble oxide. Because this occurrence would have disastrous consequences on the operation of a circulation fuel solution, a means on insuring against it was essential. The most direct method of preventing the fuel oxide formation is through the addition of $\mathrm{ZrF}_{4}$ which reacts in a similar fashion with water vapor:

$$
2 \mathrm{H}_{2} \mathrm{O}_{(\mathrm{g})}+2 \mathrm{ZrF}_{4} \rightleftarrows \mathrm{ZrO}_{2}+4 \mathrm{HF}_{(\mathrm{g})}
$$

The net reaction, by subtracting the two above would be:

$$
\mathrm{ZrF}_{4}+\mathrm{UO}_{2} \rightleftharpoons \mathrm{ZrO}_{2}+\mathrm{UF}_{4}
$$

The concentrations at equilibrium for Eq. 3 are shifted far to the right with the consequence that 
$\mathrm{ZrO}_{2}$ is formed, preferentially, to $\mathrm{UO}_{2}$, providing there is enough $\mathrm{ZrF}_{4}$ in the solution. The

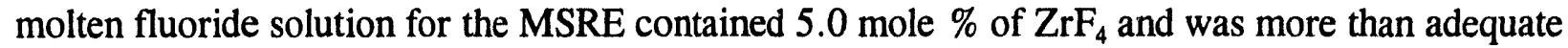
to handle any oxide impurity problems. Even though there was enough $\mathrm{ZrF}_{4}$ in the system to react with a 55 gal. drum of (liquid) water, no significant oxide was ever formed during the operating experience of the MSRE; and, consequently, it is practical to consider reducing the $\mathrm{ZrF}_{4}$ concentration (to fulfill other solution requirements) if the oxide control system is as reliable as that for the MSRE.

Reactions of the fuel or solvent with the other system components such as the metal container or the moderator graphite can also produce insoluble components. These reactions are largely governed by the second major chemical factor, redox behavior, and will be discussed in the context of how it was used to control both insolubility and corrosion mechanisms.

Redox Control. Corrosion of the metal container for molten fluoride reactor systems was also a major concern during the development of the MSRE. As a result, much effort was given to the development of a suitable metal alloy, namely, Hastelloy $\mathrm{N}$, which contains, in addition to the nickel base composition, the following percentages of: $\mathrm{Mo}, 15-18 ; \mathrm{Cr}, 6-8 ; \mathrm{Fe}, 5 ; \mathrm{C}, 0.04-0.08$; $\mathrm{Mn}, 1.0 ; \mathrm{Si}, 1.0 ; \mathrm{W}, 0.5 ; \mathrm{Al}+\mathrm{Ti}, 0.5 ; \mathrm{Cu}, 0.35 ; \mathrm{Co}, 0.2 ; \mathrm{P}, 0.015 ; \mathrm{S}, 0.02 ; \mathrm{B}, 0.01$; Others, 0.5 . Since the most reactive of the metal alloy components is $\mathrm{Cr}$, the following corrosion reaction could be expected in a uranium fueled system:

$$
\mathrm{Cr}+2 \mathrm{UF}_{4} \rightleftarrows 2 \mathrm{UF}_{3}+\mathrm{CrF}_{2}
$$

Realizing that this is an equilibrium, the corrosion reaction can be controlled by adding a substantial quantity of $\mathrm{UF}_{3}$ to the solution. The addition was however accomplished by the beryllium reduction of the $\mathrm{UF}_{4}$ already in solution according to:

$$
\mathrm{Be}+2 \mathrm{UF}_{4} \rightleftarrows \mathrm{BeF}_{2}+2 \mathrm{UF}_{3}
$$

Beryllium was conveniently added by placing the metal in a sample capsule and lowering it down the access tube into the sample cage of the pump bowl. Controlled additions of Be metal reductant were made in order to maintain the $\mathrm{UF}_{3} / \mathrm{UF}_{4}$ ratio at 0.01 . These Be additions could be made on a weekly or monthly basis to maintain, while monitoring the $\mathrm{CrF}_{2}$ content of salt samples taken from the pump bowl. In this manner the corrosion of the MSRE Hastelloy N was kept at a negligible value --- a fact that was substantiated by analysis of metal parts taken from the reactor after shutdown in 1969.

Other corrosion reactions are possible with the solvent components if they have not been thoroughly pretreated prior to usage:

$$
\begin{aligned}
& \mathrm{Cr}+\mathrm{NiF}_{2} \rightleftarrows \mathrm{CrF}_{2}+\mathrm{Ni} \\
& \mathrm{Cr}+2 \mathrm{HF} \rightleftarrows \mathrm{CrF}_{2}+\mathrm{H}_{2}
\end{aligned}
$$

These reactions were never a problem due to the hydrofluorination pretreatment of the solvents which eliminated metal ion concentrations such a $\mathrm{NiF}_{2}$ and dissolved gases such as $\mathrm{HF}$ by final inert gas sparging.

Chemical reaction of the fuel components with the moderator graphite were also of concern and involved: 


$$
\begin{aligned}
& 4 \mathrm{UF}_{4}+\mathrm{C} \rightleftarrows 4 \mathrm{UF}_{3}+\mathrm{CF}_{4} \\
& 4 \mathrm{UF}_{3}+\mathrm{xC} \rightleftharpoons 3 \mathrm{UF}_{4}+\mathrm{UC}_{\mathrm{x}}
\end{aligned}
$$

From thermodynamic values, the reaction in equation 8 is expected to produce $<10^{-8} \mathrm{~atm}$ of $\mathrm{CF}_{4}$ and none was ever seen giving assurance that graphite oxidation was unimportant. The formation of uranium carbides, as indicated in equation 9 , could occur if the $\mathrm{UF}_{3} / \mathrm{UF}_{4}$ ratio became too large. Careful control of this ratio between 0.007 and 0.02 prevented the formation of carbides, if too reducing, and corrosion products via equation 4 , if too oxidizing.

For plutonium fueled reactors, similar redox control will be necessary but will be more difficult because the $\mathrm{Pu}(\mathrm{III}) / \mathrm{Pu}$ (IV) redox couple is outside the range of stability in contact with the other reactor components. It is anticipated that redox control in plutonium fueled systems could be accomplished with $\mathrm{Ce}(\mathrm{III}) / \mathrm{Ce}(\mathrm{IV})$ additions or, preferably, by sparging with a redox gas mixture such as $\mathrm{HF} / \mathrm{H}_{2}$.

The importance of redox control is so important to the chemical behavior of molten salt reactor systems that numerous analytical techniques were developed to monitor the status. These techniques include spectrophotometry and electrochemistry (to determine the $\mathrm{UF}_{3} / \mathrm{UF}_{4}$ concentration ratio) as well as grab samples using the sampling procedure in the pump bowl followed by wet chemical analysis for U(III), U(IV) and $\mathrm{Cr}$ contents of the fuel salt. Inline spectrophotometry or electrochemistry is expected to play a significant role in future operating systems.

Redox control would be a simple matter were it not for the fact that the fission of the actinides produces changes in the redox potential of the melt. This arises because, for example, in the case of $\mathrm{UF}_{4}$ fissioning, the net oxidation state of the fission products is less than four and yet four fluorine atoms are released, leaving a slightly oxidizing event for each fission. In the case of $\mathrm{PuF}_{3}$ fission, it is expected that the net oxidation state of the fission products will be slightly greater than three while only three fluorine atoms are released to produce a slightly reducing event for each fission. This is clearly a matter that requires further investigation if plutonium fuels are to be used in future designs.

In addition to changes in the redox potential due to fission, transmutation of $\mathrm{LiF}$ and $\mathrm{BeF}_{2}$ in high neutron fluxes is expected to produce redox changes and oxide impurities which will require further consideration in future systems.

Chemical Activity. Chemical activity, per se, in the molten salt system was not of prime concern during the MSRE development. Rather, such changes were represented as shifts in the equilibrium quotients for the various metal ions in equilibrium with each other, realizing all the while that these equilibrium shifts were controlled by changes in the chemical activity. It is believed that a better understanding of the coordination chemistry of these metal ions since that time has permitted a change of focus to those factors which alter the chemical activity.

Because each metal ion tends to coordinate with ligands (ie., $\mathrm{F}^{-}$, in this case) according to their size and charge, usually discrete coordination numbers can be given for each ion, for example, $\mathrm{Be}(\mathrm{II}): 4, \mathrm{Zr}(\mathrm{IV}): 6-7, \mathrm{U}(\mathrm{IV}): 7-8$. In a Lewis acid/base concept, these are Lewis acids. Alkali metal fluorides are not so strongly attached to their corresponding fluoride ions and readily give these up so such acidic ions. Alkali metal halide melts are then thought of as basic while those deficient in fluoride ion are acidic. Equilibria such as: 


$$
\begin{aligned}
& 2 \mathrm{~F}^{-}+\mathrm{BeF}_{2} \rightleftarrows \mathrm{BeF}_{4}^{2-} \\
& 2 \mathrm{~F}^{-}+\mathrm{ZrF}_{4} \rightleftarrows \mathrm{ZrF}_{6}^{2-}
\end{aligned}
$$

with the $\mathrm{F}^{-}$supplied by the alkali metal fluoride, determine whether the solution is acidic or basic. The mixture $\mathrm{LiF}-\mathrm{BeF}_{2}\left(66-34\right.$ mole \%) if fluoride ion neutral while the mixture $\mathrm{LiF}_{-} \mathrm{ZrF}_{4}(50-50$ mole \%) is acidic.

Changes in the chemical activity are defined by:

$$
\text { a } \quad=\quad \gamma \cdot[]
$$

where $\gamma$ is the activity coefficient and [ ] is the concentration of the ion in solution. Coordination equilibria similar to those indicated in equations 10 and 11 can occur for U(IV), U(III), and any other ions in solution and over the composition range of the phase diagram, these changes can account for activity coefficient changes of several orders of magnitude. The net impact is that the equilibrium chemistry of ions in solution can change dramatically as the solvent system is varied from acidic to basic conditions Typically, the experience with molten salt systems is with the very basic (ie., $\mathrm{F}^{-}$rich) to neutral solutions. Solvent changes to very acidic systems are expected to bring on great changes in the chemistry of the system and would require much additional R\&D development if they were to be used as reactor fuels. One of the most noticible changes on going to acidic systems is a great increase in volatility of those species which are normally volatile in pure form, eg., $\mathrm{Zr}$ (IV) and $\mathrm{Be}(\mathrm{II})$, because there are not enough $\mathrm{F}^{-}$present to adequately solvate them in solution.

\section{Fission Product Behavior/Processing}

Although there was some salt processing for purposes of fission product removal in the MSRE, there still remains much to be developed for more current applications. The fissionproduct $\mathrm{Kr}$ and $\mathrm{Xe}$ were readily removed by the helium gas sparge in the pump bowl. The operation was simple because these inert gases show very low solubilities in molten mixtures such as $\mathrm{LiF}-\mathrm{BeF}_{2}(66-34$ mole \%).

Other fission products such as $\mathrm{Rb}, \mathrm{Cs}, \mathrm{Sr}, \mathrm{Ba}, \mathrm{Zr}, \mathrm{Y}$; and $\mathrm{Ln}$ form stable fluorides and are soluble in the molten salt solution. While acceptable for MSRE operations, the removal of these in current applications would be necessary for recycle of the solvent or for ultimate disposal.

The least understood are the fission products, $\mathrm{Mo}, \mathrm{Nb}, \mathrm{Ru}$, and $\mathrm{Te}$. Some, notably the first two, form cluster compounds with metal-metal bridges as in $\mathrm{Nb}_{6} \mathrm{~F}_{15}$ upon reduction from the higher oxidation states. They are expected to show a variety of unusual reaction characteristics with increasing insolubility and volatility as the reduction process continues. Disproportionation of intermediate valence states can produce insoluble lower valences accompanied by very volatile high valence species. During the operaition of the MSRE, this unusual behavior was perhaps incorrectly attributed to metal fogs in the system. Still much chemical R\&D is required to clarify this chemical behavior as a function of redox and solvent acid/base conditions.

Chemical processing in MSRE was under development primarily for intermediate removal of $\mathrm{Pa}$ during the ${ }^{232} \mathrm{Th}$ breeding cycle. Difficulties encountered in this development can be avoided because such processing will probably not be necessary ir current applications. Processing operations on molten chloride solutions as related to systems such as the Integral Fast 
Reactor fuel processing gives much encouragement that similar processes can be developed for molten fluoride processing. Removal of the lanthanides will probably be required to maximize neutron economy. Batch processing off line will probably be first utilized, only to be followed by continuous inline processing as the current systems develop.

\section{Summary}

The experience with the MSRE demonstrates that most of the molten fluoride chemistry is well known and controllable. The chemical stabilities and volatilities were easily controlled due to a well designed fuel/solvent system. Fission product behavior and separation is a major need which will require considerable R\&D. The use of plutonium fuels will lead to several uncertainties including solubility and redox control and these, along with the effects of high neutron fluxes on the molten fluoride behavior, will require further study. The future for molten salt reactor systems will certainly be driven largely by waste concerns as other systems are already experiencing. Without such an answer to the waste question, which includes recycle and adequate separation of fission product, the promise for such devices will be compromised. Ultimately, batch and/or continuous processing will become a prime necessity.

\section{Acknowledgement}

Research sponsored by the Division of Chemical Sciences, U.S. Department of Energy under contract DE-AC05-84OR21400 with Martin Marietta Energy Systems, Inc. 
Fig. 1. Cutaway view of the Molten Salt Reactor Experiment circuitry.

Fig. 2. Cutaway view of the Molten Salt Reactor Experiment fuel pump bowl.

Fig. 3. Phase diagram of $\mathrm{LiF}-\mathrm{BeF}_{2}$ 

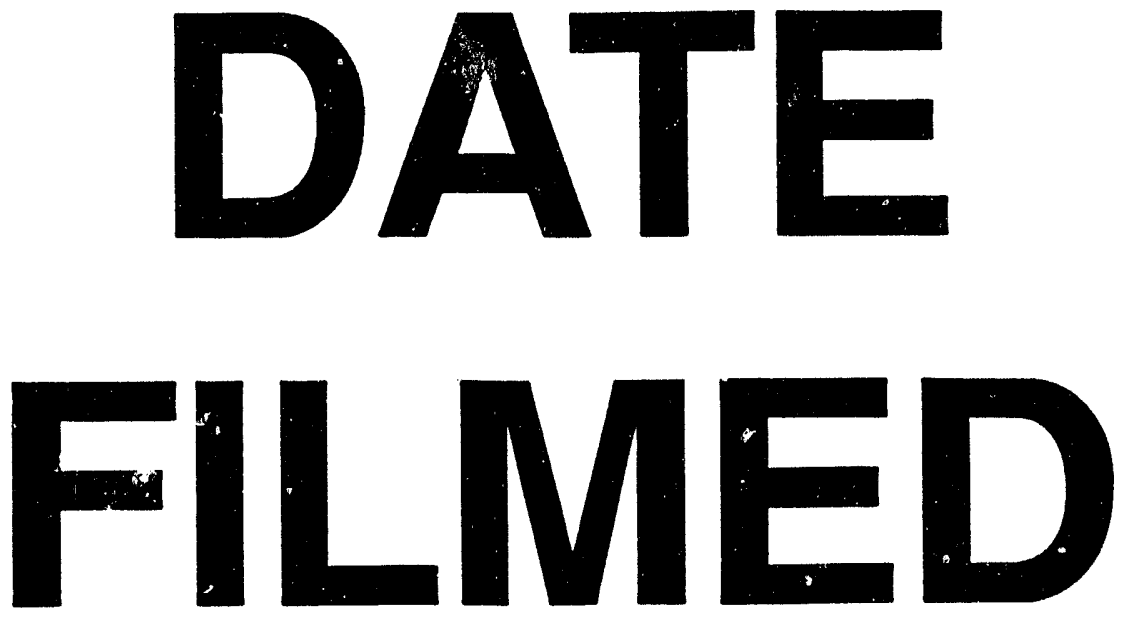

$10 / 31 / 94$
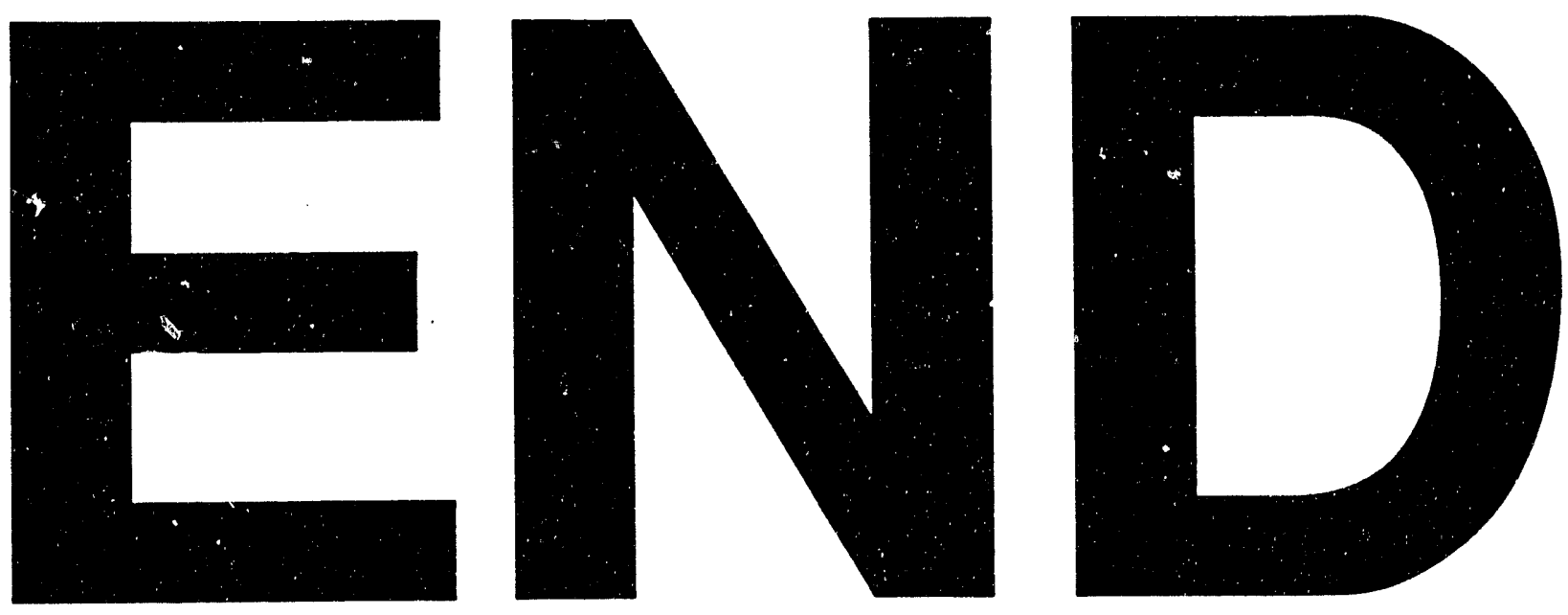
